\title{
Assessment of nonlinear site response at ocean bottom seismograph sites based on S-wave horizontal-to-vertical spectral ratios: a study at the Sagami Bay area K-NET sites in Japan
}

\author{
Yadab P. Dhakal", Shin Aoi, Takashi Kunugi, Wataru Suzuki and Takeshi Kimura
}

\begin{abstract}
We analyzed S-wave horizontal-to-vertical (S-HN) spectral ratios at six ocean bottom seismograph (OBS) sites of K-NET located in the Sagami Bay area of Japan for nonlinear site responses. The degree of nonlinearity was computed by comparing the S-H/N spectral ratios for strong motions (PGA $\geq 20 \mathrm{~cm} / \mathrm{s}^{2}$ ) with those for weak motions $\left(P G A<20 \mathrm{~cm} / \mathrm{s}^{2}\right)$. Our analyses, which showed that the weak-motion S-H/N spectral ratios differ from site to site, indicate that the underlying site geology is not uniform at the OBS sites. It was found that the threshold PGA causing a nonlinear site response is generally different from site to site. Recordings having horizontal PGAs greater than about $50-150 \mathrm{~cm} / \mathrm{s}^{2}$ display clear signatures of nonlinear site effects, i.e., the shift of predominant frequencies to lower ones and/or the decrease in high-frequency spectral ratios. We also found that the degree of nonlinearity is generally larger at the OBS sites due to the smaller threshold motions that cause a nonlinear site response compared with the available data at land sites. The above findings suggest the possibility of a widespread nonlinear site response at the OBS sites for offshore earthquakes with a large magnitude. However, frequencies lower than about $2 \mathrm{~Hz}$ are not affected by the nonlinear site response in the analyzed data ranges $\left(P G A<467 \mathrm{~cm} / \mathrm{s}^{2}\right)$. These results indicate the need for careful utilization of recorded strong motions at OBS sites for applications such as real-time ground motion predictions as front detections.
\end{abstract}

Keywords: Ocean bottom seismograph, Nonlinear site response, Horizontal-to-vertical spectral ratio, Sagami Bay

\section{Background}

Soft soil sites undergo nonlinear site responses during strong shakings. A peak ground acceleration (PGA) of $100-200 \mathrm{~cm} / \mathrm{s}^{2}$ has generally been cited as a threshold motion that causes a nonlinear site response (e.g., Beresnev and Wen 1996). The classical approach compares the spectral ratios of observed recordings at a site with respect to those at a reference rock site to identify nonlinearity. A major limitation of this approach, however, is the availability of a reference rock site that is close

\section{*Correspondence: ydhakal@bosai.go.jp}

National Research Institute for Earth Science and Disaster Resilience, Tsukuba, Japan enough to the soil site to cancel the source and propagation path effects (e.g., Field et al. 1997). In contrast, the deployment of vertical array strong-motion observations in different parts of the world provides a unique opportunity to understand linear as well as nonlinear site responses during strong shakings (e.g., Satoh et al. 1995; Wen et al. 1995; Bonilla et al. 2002; Tsuda et al. 2006). Using the surface and borehole site pairs of KiKnet stations, Wu et al. (2010) pointed out nonlinear site responses even for shakings as low as about $20-30 \mathrm{~cm} / \mathrm{s}^{2}$. The nonlinear site response is identified by the reduction in amplitude of high-frequency components and the shift of predominant frequencies to lower ones during strong motions in comparison with those during weak motions; 
these effects are due to the increase in damping and degradation of the shear rigidity of soils during strong shakings (e.g., Beresnev and Wen 1996).

Wen et al. (2006) proposed a single station method using the horizontal-to-vertical spectral ratios of S-waves $(\mathrm{S}-\mathrm{H} /$ $\mathrm{V})$ to identify the nonlinear site effects. In this method, the mean S-H/V spectral ratios for weak motions at a site are considered to be the reference spectral ratios and are compared with the S-H/V spectral ratios for strong motions at the same site. Using the method of Wen et al. (2006), Noguchi and Sasatani $(2008,2011)$ identified the nonlinear site effects at KiK-net sites during strong shakings; it was verified that the $\mathrm{S}-\mathrm{H} / \mathrm{V}$ spectral ratios of surface recordings have features similar to those depicted by the surface and borehole station pairs. The S-H/V method is especially useful for sites where the station pairs or vertical array measurements are unavailable.

Deployments of large-scale ocean bottom networks that comprise seismometers and pressure gauges (e.g., DONET in the Nankai Trough area, DONET 2016; S-net in the Japan Trench area, Kanazawa 2013) are expected to contribute to earthquake and tsunami early warnings by prompt detection of earthquakes at subduction zones. The amplification effects of soft sediments at the ocean bottom seismograph (OBS) sites on the overestimation of displacement-amplitude-based magnitudes have already been discussed (Hayashimoto and Hoshiba 2013; Nakamura et al. 2014). Hayashimoto et al. (2014) analyzed the S-H/V spectral ratios at three off Kushiro OBS sites and showed that recordings having a PGA of about $100 \mathrm{~cm} /$ $\mathrm{s}^{2}$ or greater display the nonlinear site response. These results indicated that the reliable prediction of strong motions using the OBS sites as front stations is impossible without taking the nonlinear site effects into account. In this regard, it is important to identify nonlinear site response characteristics such as threshold PGAs, shift of predominant frequencies, and reduction in high-frequency amplifications at the OBS sites to effectively utilize the strong-motion recordings at the OBS sites for real-time applications.

Because the OBS sites are located several kilometers away from the land stations and do not have deep vertical array observations, the $\mathrm{S}-\mathrm{H} / \mathrm{V}$ spectral ratio method is useful for the identification of nonlinear site responses at the OBS sites. Many weak-motion recordings and several strong-motion recordings exceeding $100 \mathrm{~cm} / \mathrm{s}^{2}$ are available at each of the six Sagami Bay area OBS sites. In this paper, we apply the $\mathrm{S}$-wave $\mathrm{H} / \mathrm{V}$ spectral ratio method to investigate the nonlinear site effects at the Sagami Bay area OBS sites, namely the KNG201, KNG202, KNG203, KNG204, KNG205, and KNG206 sites (Fig. 1). The data from these OBS sites are available as a part of the K-NET observation system (Aoi 2004). The distance interval

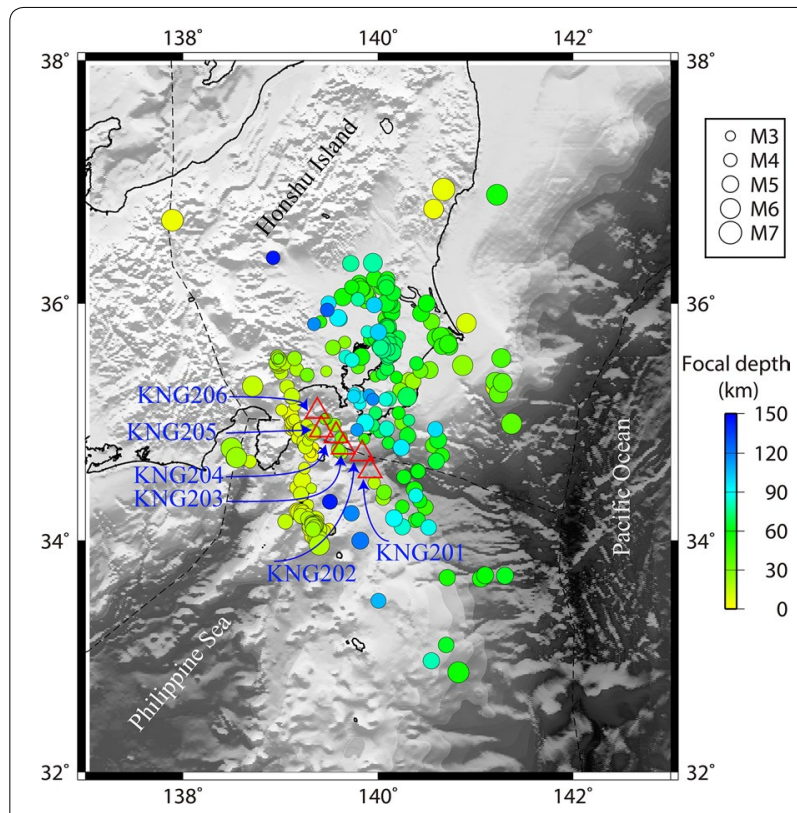

Fig. 1 Location map. Triangles denote the OBS sites, namely KNG201 (farthest off-shore site), KNG202, KNG203, KNG204, KNG205, and KNG206 (nearest off-shore site) in the Sagami Bay area from east to west, respectively. Circles, which are scaled by magnitude, denote the epicenters of the earthquakes used in this study. The filled colors of the circles denote the focal depths of the earthquakes. The depths to ocean bottoms from the KNG201 to the KNG206 sites are 2197, $2339,902,933,1486$, and $1130 \mathrm{~m}$, respectively. The background color denotes the elevation of the land and ocean bottoms, and the deepest elevation is the darkest color

between two adjacent OBS sites is approximately $20 \mathrm{~km}$, and the depths of oceanic water range between about 1000 and $2000 \mathrm{~m}$. Details about the deployment of the OBS sites used in this study can be found in Eguchi et al. (1998).

\section{Data and methodology}

We used 935 three-component ocean bottom accelerograms from 315 earthquakes. The accelerograms have the following properties: (1) horizontal vector PGA $>5 \mathrm{~cm} / \mathrm{s}^{2}$, (2) both P- and S-wave onsets are included in the recordings, and (3) signal-to-noise ratio is greater than 3 for each frequency component. In this paper, we define the PGA as the horizontal vector PGA obtained from two horizontal component recordings. The epicenters of the earthquakes used in this study are shown in Fig. 1. We used recordings from earthquakes having Japan Meteorological Agency magnitudes (Mj) between $M j=3$ and $M j=7$. Most of the recordings having PGAs $>20 \mathrm{~cm} / \mathrm{s}^{2}$ are from earthquakes between $M j=4.0$ and $M j=6.6$. An example of recordings with pre-event noise, S-wave time windows, and their Fourier amplitude spectra is shown in Additional file 1 . The epicentral distance was arbitrarily restricted to $200 \mathrm{~km}$ for recordings having PGA $<20 \mathrm{~cm} /$ 
$\mathrm{s}^{2}$ to reduce the data processing time because a large number of recordings are available for smaller motions and to $300 \mathrm{~km}$ for recordings having PGA $\geq 20 \mathrm{~cm} / \mathrm{s}^{2}$ to increase the number of such strong-motion recordings. The focal depths of the earthquakes were shallower than $150 \mathrm{~km}$.

Wu et al. (2010) noted a time window of $6 \mathrm{~s}$ as a balance between the stability of the computed spectra and the temporal changes for recordings from earthquakes with relatively smaller magnitudes. In this study, we used a time window of $10 \mathrm{~s}$ starting from $1 \mathrm{~s}$ before the $\mathrm{S}$-wave onset considering the stability of the computed spectra as temporal changes were not investigated. We picked the S-wave onset manually, and half-cosine tapering was applied for $1 \mathrm{~s}$ at both ends of the time window. The time window was extended to $40.96 \mathrm{~s}$ by padding zeroes to compute the Fourier spectral amplitudes. The horizontal spectral amplitudes were derived as the vector sum of two horizontal components, and both horizontal and vertical spectral amplitudes were smoothed by applying a Parzen window of $0.4 \mathrm{~Hz}$. Then, S-H/V spectral ratios were obtained.

We adopted the equation (Eq. 1) proposed by Noguchi and Sasatani (2008) to quantify the degree of nonlinearity (DNL) based on the S-H/V spectral ratios. The equation is shown below.

$$
\mathrm{DNL}=\sum\left|\log \left\{\frac{R_{\text {strong }}}{R_{\text {weak }}}\right\}\right| \Delta f
$$

where $R_{\text {strong }}$ and $R_{\text {weak }}$ represent the $\mathrm{S}-\mathrm{H} / \mathrm{V}$ spectral ratios for strong motions and weak motions, respectively, and $\Delta f$ is the frequency interval. One of the advantages of this DNL index is that it gives a single value that facilitates the comparison with other parameters such as the PGA. We calculated the DNL from spectral ratios between $0.5 \mathrm{~Hz}$ and $20 \mathrm{~Hz}$. An example plot of $\mathrm{S}-\mathrm{H} / \mathrm{V}$ spectral ratios from two groups of recordings, PGA $<20 \mathrm{~cm} / \mathrm{s}^{2}$ and $20 \mathrm{~cm} /$ $\mathrm{s}^{2} \leq \mathrm{PGA} \leq 50 \mathrm{~cm} / \mathrm{s}^{2}$, is shown in Additional file 2 for the KNG201 site. We found that the mean spectral ratios for the two groups of recordings are nearly identical. We adopted the mean spectral ratios from recordings having PGA $<20 \mathrm{~cm} / \mathrm{s}^{2}$ as $R_{\text {weak }}$ and spectral ratios from recordings having PGA $\geq 20 \mathrm{~cm} / \mathrm{s}^{2}$ as $R_{\text {strong }}$ for all sites. Noguchi and Sasatani (2011) suggested a DNL value of 4 to identify the nonlinear site response in consideration of the stability of the S-H/V spectral ratios for individual recordings. Our preliminary results (Dhakal et al. 2016) support that this value of DNL is reasonable to identify the nonlinear site response when using the same processing techniques of Noguchi and Sasatani (2011) to derive the spectral ratios. A comparison of the weak-motion mean S-H/V spectral ratios $\left(R_{\text {weak }}\right)$ at the six OBS sites is shown in Fig. 2. The $R_{\text {weak }}$ values, computed from 60 to 115 recordings (earthquakes) at each site (see Additional file 2, for an example), show that the peak frequencies are different from site to site. This difference suggests that the local geology is generally different from site to site (e.g., Kawase et al. 2011), and the degree of nonlinear site response is also expected to be different at each site, as described in the next section.

\section{Results and discussion}

We obtained the DNL at each of the OBS sites by using the methodology described in the previous section. We show a comparison of the $\mathrm{S}-\mathrm{H} / \mathrm{V}$ spectral ratios of the weak motion with those of the strong motion at the KNG201 and KNG203 sites in Fig. 3a, b, respectively, for selected recordings having PGA $>100 \mathrm{~cm} / \mathrm{s}^{2}$. The DNL values are also shown for each recording. Similar comparisons at the KNG202, KNG204, KNG205, and KNG206 sites are provided in Additional file 3. Here, the KNG201 and KNG203 sites are selected to illustrate how closely the DNL values and other features such as the shift of periods and the decrease in high-frequency components change with shaking levels. Also, the KNG201 and KNG203 sites have S-H/V spectral ratios of the weak-motion peak at somewhat separated frequencies, as shown in Fig. 2. Thus, the comparison clarifies the site response behavior between two different site conditions. Figure 3 a shows the comparison of $\mathrm{S}-\mathrm{H} / \mathrm{V}$ spectral ratios for four recordings having PGAs $123,124,192$, and $247 \mathrm{~cm} / \mathrm{s}^{2}$ at the KNG201 site. S-H/V spectral ratios of the weak motion show a broader peak from 1 to $2 \mathrm{~Hz}$ at the KNG201 site. No clear shift of

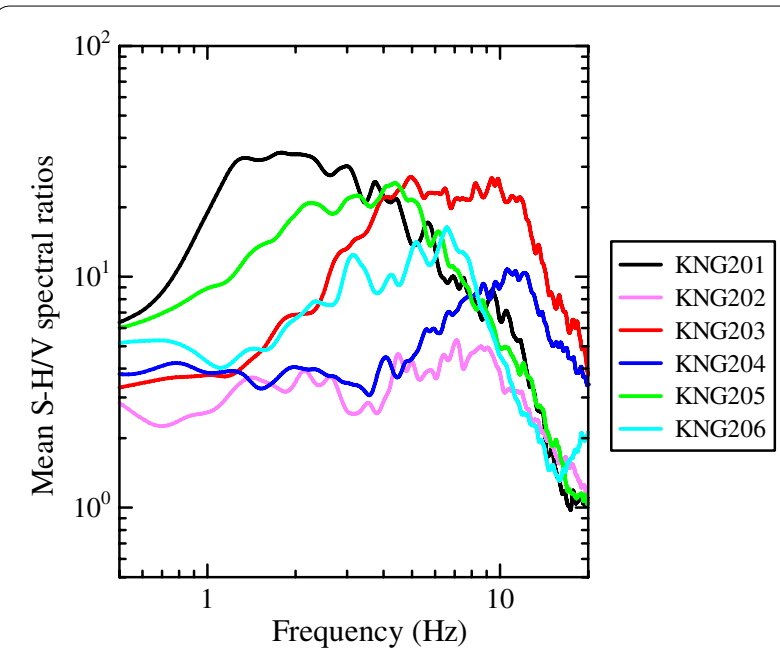

Fig. 2 Comparison of mean S-H/N spectral ratios for weak motions at the OBS sites. The spectral ratios for each site are denoted by different colors 

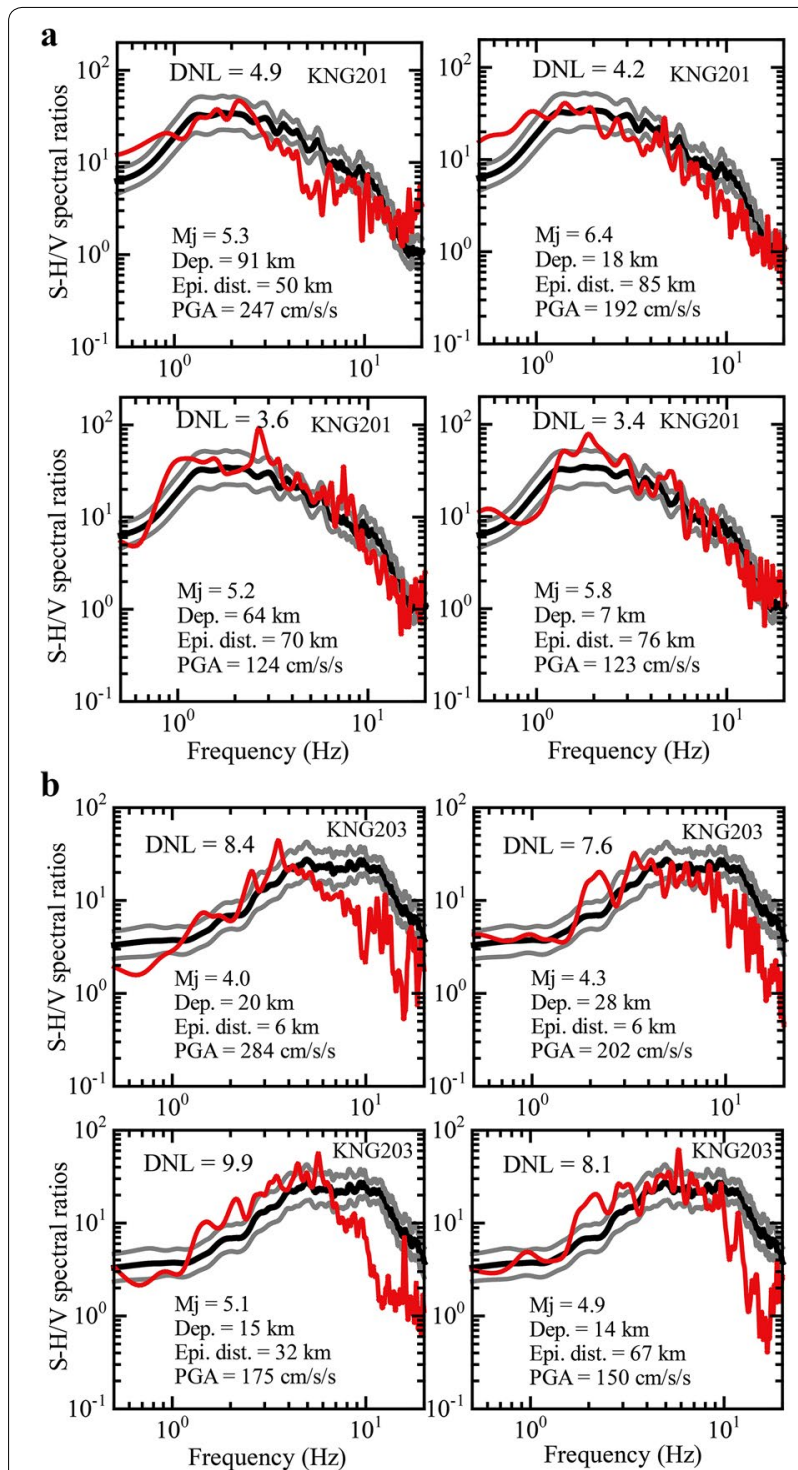

Frequency $(\mathrm{Hz})$
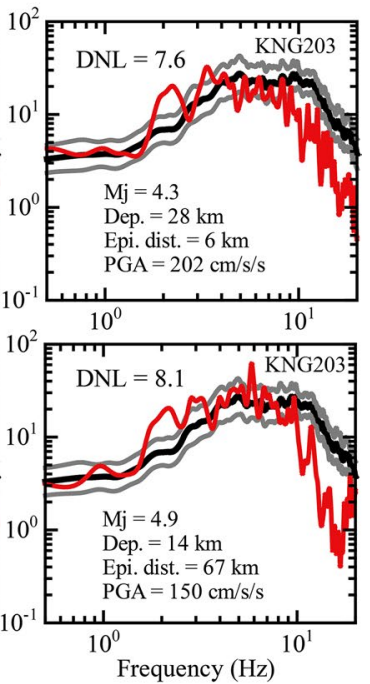

Fig. 3 Comparison of weak-motion (PGA $<20 \mathrm{~cm} / \mathrm{s}^{2}$ ) mean spectral ratios with strong-motion spectral ratios from four individual events recorded with PGA $>100 \mathrm{~cm} / \mathrm{s}^{2}$ at the a KNG201 and b KNG203 sites. The black lines denote the weak-motion mean spectral ratios. The gray lines denote the range of one standard deviation. The red lines denote the strong-motion spectral ratios for individual events. The magnitude, focal depth, epicentral distance, PGA, and DNL for each strong-motion event are provided inside each frame

peak frequency and systematic reduction in high-frequency spectral ratios can be identified at the KNG201 site for the four strong-motion recordings mentioned above. For the first two recordings having PGAs 123 and $124 \mathrm{~cm} / \mathrm{s}^{2}$, the DNL values are smaller than 4 . For the other two recordings having PGAs 192 and $247 \mathrm{~cm} /$ $\mathrm{s}^{2}$, the DNL values are 4.2 and 4.9 , respectively. However, a close examination of the spectral ratios for the
$247 \mathrm{~cm} / \mathrm{s}^{2}$ recording shows an opposite trend of the spectral ratios at a frequency of about $20 \mathrm{~Hz}$. This trend suggests that the DNL value for this recording is exaggerated. In summary, the KNG201 site has a small nonlinear site response even for a PGA of about $200 \mathrm{~cm} / \mathrm{s}^{2}$.

A comparison of the $\mathrm{S}-\mathrm{H} / \mathrm{V}$ spectral ratios at the KNG203 site for four recordings having PGAs 150, 175, 202, and $284 \mathrm{~cm} / \mathrm{s}^{2}$ is shown in Fig. 3b. S-H/V spectral ratios of the weak motion at the site show peak frequencies between 5 and $10 \mathrm{~Hz}$. Unlike the KNG201 site, a clear decrease in high-frequency spectral ratios between 7 and $20 \mathrm{~Hz}$ can be seen for all of the PGAs mentioned above, and the clear shift of peak frequencies to lower ones can be identified for the two largest PGAs. The computed DNL values are greater than 7.5 and agree with the visual comparisons from which substantial nonlinearity can be stipulated. It is noted that the largest PGA in the analyzed data is $467 \mathrm{~cm} / \mathrm{s}^{2}$ recorded at the KNG205 site; the DNL value is 7.3; and a clear shift of peak frequency and reduction in highfrequency spectral ratios can be identified (see Additional file 3). Our analysis indicated that the spectral ratios at frequencies lower than $2 \mathrm{~Hz}$ are not affected by the nonlinear site response in the analyzed data ranges.

The relationship between the PGAs and DNL values is summarized in Fig. $4 \mathrm{a}-\mathrm{f}$ for the six OBS sites. The flattened trend of the DNL values at lower PGAs indicates that the site response is linear for these recordings. At the KNG201, KNG202, and KNG206 sites, the DNL values are less than 4 for PGAs less than about

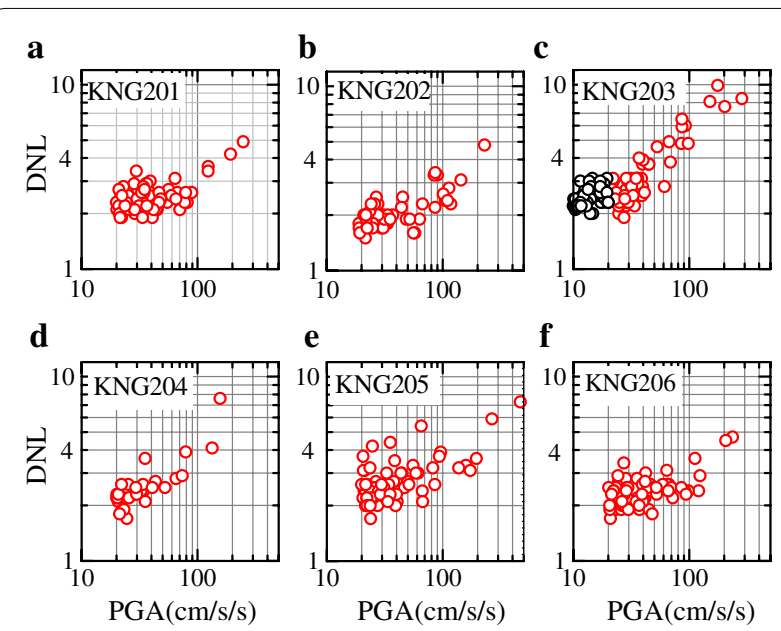

Fig. 4 Plot of DNL values against PGAs at the OBS sites. a-f The relationships between the DNL values and PGAs from the KNG201 to the KNG206 sites, respectively. The DNL values plotted at c for PGAs between $10 \mathrm{~cm} / \mathrm{s}^{2}$ and less than $20 \mathrm{~cm} / \mathrm{s}^{2}$ (black colored circles) were obtained with respect to the weak motions having PGAs between $5 \mathrm{~cm} / \mathrm{s}^{2}$ and less than $10 \mathrm{~cm} / \mathrm{s}^{2}$. See the text for details 
$150 \mathrm{~cm} / \mathrm{s}^{2}$ and then increase almost similarly with the increase in PGAs. At the KNG203 site, the DNL values are larger than 4 for PGAs larger than about $50 \mathrm{~cm} /$ $\mathrm{s}^{2}$ and increase linearly with the increase in PGAs. Because the nonlinearity appears at relatively lower PGAs at the KNG203 site, the flattened trend of the DNL values cannot be recognized well between 20 and $50 \mathrm{~cm} / \mathrm{s}^{2}$. Therefore, at the KNG203 site, we added the DNL values computed for $10 \mathrm{~cm} / \mathrm{s}^{2}$ to less than $20 \mathrm{~cm} /$ $\mathrm{s}^{2}$ recordings with respect to the mean spectral ratios computed from 39 recordings having PGAs between $5 \mathrm{~cm} / \mathrm{s}^{2}$ and less than $10 \mathrm{~cm} / \mathrm{s}^{2}$. The added data helped to clearly see the flattened trend of the DNL values at PGAs less than about $40 \mathrm{~cm} / \mathrm{s}^{2}$ (see Fig. 4c) and indicate a linear response at lower PGAs. Because the mean spectral ratios for weak motions in the two groups, $5-10 \mathrm{~cm} / \mathrm{s}^{2}$ and 10 to $20 \mathrm{~cm} / \mathrm{s}^{2}$, are found to be essentially identical, the DNL values for recordings having PGAs $\geq 20 \mathrm{~cm} / \mathrm{s}^{2}$ are not discussed further with respect to the mean spectral ratios for $5-10 \mathrm{~cm} / \mathrm{s}^{2}$ recordings. At the KNG204 site, the DNL values are less than 4 for PGAs less than about $100 \mathrm{~cm} / \mathrm{s}^{2}$ and rise sharply at PGAs of about $150 \mathrm{~cm} / \mathrm{s}^{2}$. The KNG205 site shows larger variability for smaller PGAs less than about $100 \mathrm{~cm} / \mathrm{s}^{2}$, with DNL values occasionally rising over 4 . On average, the DNL value is smaller than 4 for PGAs less than about $200 \mathrm{~cm} / \mathrm{s}^{2}$ and larger than 4 for PGAs larger than about $200 \mathrm{~cm} / \mathrm{s}^{2}$ at the KNG205 site. The relationship between the DNL values and PGAs suggests that the sites behave nonlinearly only after reaching the threshold PGA, which generally varies from site to site. These results are consistent with the fact that the soil response is linear at small strain levels and behaves nonlinearly at large strains.

As we applied the same processing technique as Noguchi and Sasatani (2011), it is interesting to see how the DNL values obtained at the OBS sites and those obtained at the land sites by Noguchi and Sasatani (2011) are different with respect to the values of PGAs. The results from the present study and those from Table 1 of Noguchi and Sasatani (2011) are compared in Additional file 4. We found that the DNL values at the land sites and four OBS sites, namely KNG201, KNG202, KNG205, and KNG206, change almost similarly with the comparable PGAs. However, at two OBS sites, KNG203 and KNG204, the DNL values for PGAs of about $200 \mathrm{~cm} / \mathrm{s}^{2}$ are about twice the DNL values for the corresponding PGAs at the land sites. These results are not surprising given the possibility of very soft site conditions at the OBS sites, where the nonlinear site response may begin at much lower levels of shakings. Furthermore, strong attenuation of highfrequency motions due to the soft layers at the OBS sites is possible.

Finally, we compare the peak frequencies and spectral ratios at the peak frequencies of weak motions between the weak-motion (PGA $<20 \mathrm{~cm} / \mathrm{s}^{2}$ ) and selected strongmotion recordings (PGA $>100 \mathrm{~cm} / \mathrm{s}^{2}$ ) in Fig. 5a, b, respectively. The conceptual plot shown in Fig. $5 \mathrm{c}$ defines the peak frequencies and spectral ratios for the comparison between the weak and strong motions. It can generally be seen that the peak frequencies of strong motions are lower than the peak frequencies of weak motions; the shift of peak frequencies occurs between about 20 and $55 \%$ depending on the site (Fig. 5a). For example, the shift

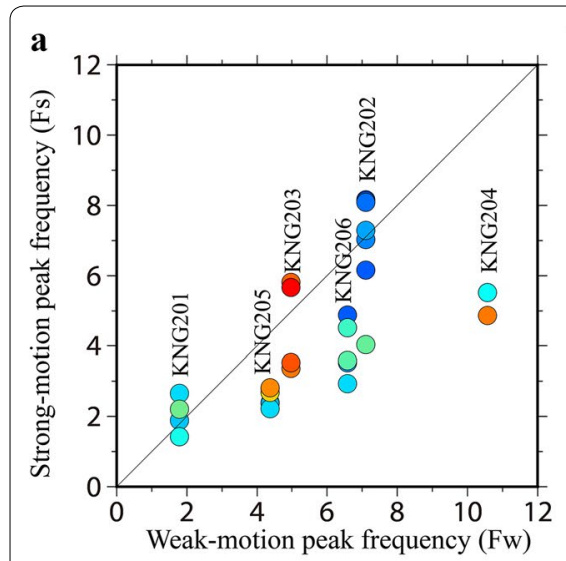

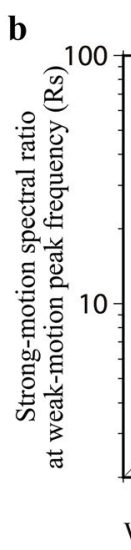

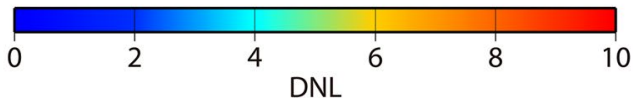

c

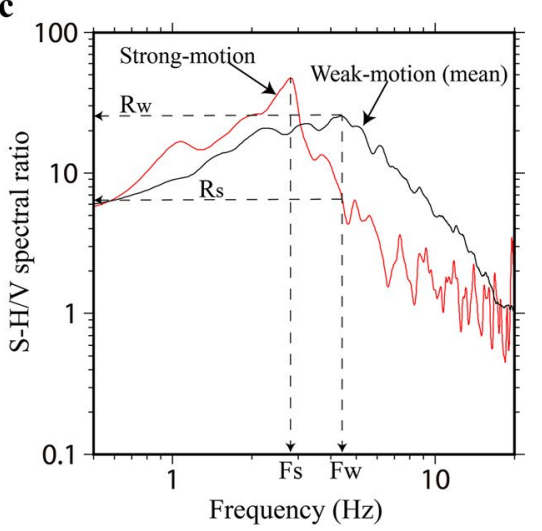

Fig. 5 a Comparison of peak frequencies between weak-motion (PGA $<20 \mathrm{~cm} / \mathrm{s}^{2}$ ) and strong-motion (PGAs $\left.>100 \mathrm{~cm} / \mathrm{s}^{2}\right) \mathrm{S}-\mathrm{H} / \mathrm{N}$ spectral ratios. b Comparison of weak-motion peak spectral ratios with strong-motion (PGAs $>100 \mathrm{~cm} / \mathrm{s}^{2}$ ) spectral ratios at the peak frequencies of weak motions. c Example plot depicting the peak frequencies compared in (a) and the spectral ratios compared in (b) 
of peak frequencies for strong motions can clearly be seen for the KNG204 and KNG206 sites (see also the additional files). However, it is sometimes difficult to quantify the shift of peak frequencies, even though a clear decrease in high-frequency spectral ratios can be observed (see lower panels of Fig. 3b); this is due to the relatively wide peak at some sites. Figure $5 \mathrm{~b}$ shows a plot of spectral ratios for strong motions at the peak frequency of weak motions against the peak spectral ratios for weak motions. The tendency for reduction in the peak spectral ratios can clearly be seen at the sites where the values of the DNL are large. The reduction in spectral ratios occurs in about $5-70 \%$ of the peak spectral ratios for weak motions in the analyzed data ranges. Again, the reduction in peak spectral ratios cannot be well quantified for some recordings due to the broader peak at some of the sites. In such cases, the DNL values, however, are still large and suggest the nonlinear site response at these sites. We find that the shift of peak frequencies and reduction in peak spectral ratios are generally larger for stronger motions at the same site. These results are similar to those reported in Wu et al. (2010) for some KiK-net sites.

\section{Conclusions}

We analyzed S-H/V spectral ratios for identifying the nonlinear site responses at six OBS sites of K-NET located in the Sagami Bay area of Japan. S-H/V spectral ratios from weak motions having PGA $<20 \mathrm{~cm} / \mathrm{s}^{2}$ were used as reference spectra for each OBS site. We found that the weak-motion $\mathrm{S}-\mathrm{H} / \mathrm{V}$ spectral ratios differ from site to site. The difference suggests that the local geology is not uniform beneath the recording stations. The degree of nonlinearity was computed by using the method proposed by Noguchi and Sasatani (2008, 2011) for recordings having PGA $\geq 20 \mathrm{~cm} / \mathrm{s}^{2}$. Our results showed that the S-H/V spectral ratios for strong-motion recordings having horizontal PGAs greater than $50-150 \mathrm{~cm} / \mathrm{s}^{2}$, depending on the site, display signatures of a nonlinear site response at the OBS sites. That is, the shift of peak frequencies to lower ones and the decrease in high-frequency spectral ratios are well identified above the threshold PGAs, which are site dependent. We found that the degree of nonlinearity was remarkably larger at some of the OBS sites due to the smaller threshold motions to cause a nonlinear site response at the OBS sites. The lower threshold PGAs at some of the OBS sites might indicate that pervasive nonlinear site effects occur at the OBS sites during offshore earthquakes of large magnitude and greatly diminish the high-frequency components of strong motions and cause a considerable shift of peak frequencies to lower ones. These results suggest the need for careful use of the recorded strong motions at the OBS sites for applications such as real-time ground motion predictions as front detections.

\section{Additional files}

Additional file 1. Example of waveform recordings and Fourier amplitude spectra.

Additional file 2. Example plot of S-H/V spectral ratios for different groups of PGAs at the KNG201 site.

Additional file 3. Comparison between weak-motion and strong-motion S-H/N spectral ratios at the KNG202, KNG204, KNG205, and KNG206 sites.

Additional file 4. Relationship between DNL values and PGAs at the OBS and land sites.

\section{Abbreviations}

DNL: degree of nonlinearity; DONET: dense oceanfloor network system for earthquakes and tsunamis; JMA: Japan Meteorological Agency; KiK-net: Kiban Kyoshin network; K-NET: Kyoshin network; OBS: ocean bottom seismographs; PGA: peak ground acceleration; S-H/V: S-wave horizontal to vertical; S-net: seafloor observation network for earthquake and tsunami along the Japan Trench.

\section{Authors' contributions}

YPD analyzed the data, interpreted the results, and drafted the manuscript. SA took part in the interpretation of the results and design of the study. TK, WS, and TK took part in the design of the study. All authors read and approved the final manuscript.

\section{Acknowledgements}

We would like to thank the Japan Meteorological Agency for providing us with hypocenter information of the earthquakes used in this study. We are grateful to two anonymous reviewers for their constructive and helpful comments that improved the quality of the manuscript. We also are grateful to Yasuo Ogawa, Editor-in-Chief, Masato Furuya, Editor, and Kuo-Liang Wen, Lead Guest Editor, at Earth, Planet and Space for facilitating the review of this manuscript. We also would like to thank Wessel and Smith (1998) for providing us with Generic Mapping Tools, which were used to make some figures in this manuscript.

\section{Competing interests}

The authors declare that they have no competing interests.

Received: 3 October 2016 Accepted: 2 February 2017

Published online: 08 February 2017

\section{References}

Aoi S (2004) Strong-motion seismograph network operated by NIED: K-NET and KiK-net. J Jpn Assoc Earthq Eng 4(3):65-74

Beresnev IA, Wen KL (1996) Nonlinear soil response-a reality? Bull Seismol Soc Am 86:1964-1978

Bonilla FL, Steidl JH, Gariel JC, Archuleta RJ (2002) Borehole response studies at the Garner Valley downhole array, Southern California. Bull Seismol Soc Am 92:3165-3179

Dhakal YP, Suzuki W, Kimura T, Kunugi T, Aoi S (2016) Analysis of S-wave H/V spectral ratios at the ocean bottom strong motion sites for soil nonlinearity. In: 5th IASPEI/IAEE international symposium: effects of surface geology on seismic motion, Aug 15-17, 2016, Taipei, Taiwan, I102C

DONET (Dense Oceanfloor Network System for Earthquakes and Tsunamis) 2016. https://www.jamstec.go.jp/donet/e/. Accessed 9 Sep 2016

Eguchi T, Fujinawa Y, Fujita E, Iwasaki SI, Watabe I, Fujiwara H (1998) A realtime observation network of ocean-bottom-seismometers deployed at the Sagami trough subduction zone, central Japan. Mar Geophys Res 20:73-94 
Field EH, Johnson PA, Beresnev IA, Zeng Y (1997) Nonlinear ground-motion amplification by sediments during the 1994 Northridge earthquake. Nature 390:599-602

Hayashimoto N, Hoshiba M (2013) Examination of travel time correction and magnitude correction of Tonankai ocean bottom seismographs for earthquake early warning. Quart J Seismol 76:69-81 (in Japanese with English abstract)

Hayashimoto N, Nakamura T, Hoshiba M (2014) The characteristics of unusual OBS data exposed to strong shaking and the influence of applying these data to EEW processing: examples of Off-Kushiro OBS, JAMSTEC. AGU Fall Meeting, S33C-4543

Kanazawa T (2013) Japan trench earthquake and tsunami monitoring network of cable-linked 150 ocean bottom observatories and its impact to earth disaster science. Underwater Technology Symposium (UT), 2013 IEEE International, 1-5. doi:10.1109/UT.2013.6519911

Kawase H, Sanchez-Sesma FJ, Matsushima S (2011) The optimal use of horizontal-to-vertical spectral ratios of earthquake motions for velocity inversions based on diffuse-field theory for plane waves. Bull Seismol Soc Am 101:2001-2014

Nakamura T, Nakano M, Hayashimoto N, Takahashi T, Takenaka H, Okamoto T, Araki E, Kaneda Y (2014) Anomalously large seismic amplifications in the seafloor area off the Kii peninsula. Mar Geophys Res 35:255-270

Noguchi S, Sasatani T (2008) Quantification of degree of nonlinear site response. In: 14th world conference on earthquake engineering, Beijing, paper ID: 03-03-0049
Noguchi S, Sasatani T (2011) Nonlinear soil response and its effects on strong ground motions during the 2003 Miyagi-Oki intraslab earthquake. Zisin 63:165-187 (in Japanese with English abstract)

Satoh T, Sato T, Kawase H (1995) Nonlinear behavior of soil sediments identified by using borehole records observed at the Ashigara Valley, Japan. Bull Seismol Soc Am 85:1821-1834

Tsuda K, Steidl J, Archuleta R, Assimaki D (2006) Site-response estimation for the 2003 Miyagi-Oki earthquake sequence considering nonlinear site response. Bull Seismol Soc Am 96:1474-1482

Wen KL, Beresnev IA, Yeh YT (1995) Investigation of nonlinear site amplification at two downhole strong ground motion arrays in Taiwan. Earthq Eng Struct Dyn 24(313):324

Wen KL, Chang TM, Lin CM, Chiang HJ (2006) Identification of nonlinear site response using the $\mathrm{H} / \mathrm{V}$ spectral ratio method. Terr Atmos Ocean Sci 17(3):533-546

Wessel P, Smith WHF (1998) New improved version of generic mapping tools released. EOS Trans AGU 79:579

Wu C, Peng Z, Ben-Zion Y (2010) Refined thresholds for non-linear ground motion and temporal changes of site response associated with mediumsize earthquakes. Geophys J Int 182(3):1567-1576

\section{Submit your manuscript to a SpringerOpen ${ }^{\circ}$ journal and benefit from:}

- Convenient online submission

- Rigorous peer review

- Immediate publication on acceptance

- Open access: articles freely available online

- High visibility within the field

- Retaining the copyright to your article 